\title{
Measuring transit-oriented development (TOD) network complementarity based on TOD node typology
}

\author{
Runjie Huang \\ ITDP China-Institute for Transport and \\ Development Policy \\ r.huang@student.utwente.nl
}

\section{Mafalda Madureira}

University of Twente

m.madureira@utwente.nl

\author{
Anna Grigolon \\ University of Twente \\ a.b.grigolon@utwente.nl
}

Abstract: Recent research on the assessment of transit-oriented development (TOD) has focused on individual transit nodes. However, we argue that having such a TOD level value is not sufficient to understand the role each transit node plays within a TOD network. In other words, a transit node may have a low performance when evaluating its individual TOD level, but it may serve an important role within the TOD network, for example, as a feeder node. In this paper, a TOD typology was developed based on built-form indicators to identify the roles different types of nodes play within the transit network and to discuss complementarity effects between TOD nodes within the TOD network. The study area is the Arnhem-Nijmegen city region in the Netherlands, which has a TOD network of 22 train stations. Results identified three types of roles: suburban residential, characterized by low population and job densities; urban residential, marked by low destination accessibility and low diversity of land-uses; and urban mixed core, which featured higher densities of jobs, population, and diversity of land uses. Based on the TOD typology, a correspondence analysis was conducted to measure the potential complementarity effect of the TOD network system, i.e., the extent to which nodes in different typologies can complement each other to strengthen the characteristics of the TOD as a network. The results illustrated that differentiation among the TOD nodes in terms of residential housing prices and building uses contributed to a more diversified offer in terms of activities and functions of the TOD region and indicates complementarity between stations. Thus, TOD should be assessed and planned in a network system perspective, with the understanding that the nodes are pieces that contribute to the performance of the network.

Keywords: Transit-oriented development, TOD typology, TOD network, network complementarity

Copyright 2018 Runjie Huang, Anna Grigolon, Mafalda Madureira, \& Mark Brussel http://dx.doi.org/10.5198/jtlu.2018.1110

ISSN: 1938-7849 | Licensed under the Creative Commons Attribution - Noncommercial License 4.0

The Journal of Transport and Land Use is the official journal of the World Society for Transport and Land Use (WSTLUR) and is published and sponsored by the University of Minnesota Center for Transportation Studies. This paper is also published with additional sponsorship from WSTLUR.

\section{Article history:}

Received: November 13, 2016

Received in revised form: May

15,2017

Accepted: December 11, 2017

Available online: March 14,

2018 


\section{Introduction}

As a planning tool that integrates transport and land use, transit-oriented development (TOD) is a promising approach to promote transit patronage and dissuade citizens from the usage of the private automobile. It is typically understood as the development of transit stations around high-density mixed land use and walkable and cycling-friendly designed environments. Density, Diversity and Design are disseminated as three of the most important dimensions of TOD (Cervero \& Kockelman, 1997). It is such a development located at a rapid transit system that can compete with automobiles in long trips and attract more people to walk or cycle in short trips. This can lead to lower usage of the automobile and a denser urban fabric, consequently, less consumption of fossil fuel and concentrated opportunities and services (Calthorpe, 1993; Cervero \& Kockelman, 1997; Cervero, Murphy, Feerell, Goguts, \& Tsai, 2004). Two new criteria of the built environment were later added: Destination accessibility and Distance to transit (Ewing \& Cervero, 2001). Destination accessibility refers to the ease of access to trip attractions, and Distance to transit is the factor measured as an average of the shortest street routes from the residences or workplaces to the nearest transit node.

These 5D criteria are often interrelated (e.g., Ewing (2008) argues that since density and diversity coexist, many of their benefits are inextricable) and even overlap (e.g., to some extent, diversity and destination accessibility are related to trip attraction (Ewing \& Cervero, 2010). The interrelation shows that the criteria of TOD are not isolated, which also indicates that the implementation of TOD should be multi-dimensional. This means that one must consider not only, i.e., number of destinations available at a specific transit station, or the diversity of land uses provided at the node level, but also how to enhance non-motorized forms of mobility within the node. These are aspects that reinforce each other.

When implemented correctly, the potential benefits of TOD are manifold. Cervero and Murakami (2009) found that TOD is well suited for financing railway infrastructures, especially in the cases characterized by high densities, and demonstrate how the investment in TOD might be paid off with the increase in transit patronage and the gaining from higher real estate prices. In the case of suburbanization, TOD can also be adopted to address the problem of declining accessibility. Cervero and Day (2008) found that relocation to the suburban areas near a transit station could help manage the decline in job accessibility, encouraging more people to take transit. Studies also find that TOD has positive effects in creating vibrant, rich and livable urban places, increasing physical activities and thus enhancing the public health and quality of life (Frank, 2000; Dittmar \& Poticha, 2004). From these points of views, it can be concluded that ideally a TOD is multi-functional, as its intended outcomes are manifold such as to reduce sprawl, increase transit ridership and reduce car use.

Recent research has been focusing on assessing the performance of individual transit nodes within a TOD network, using methods such as Spatial Multiple Criteria Analysis (SMCA) (Singh et al., 2014), to arrive at an aggregated level of TOD value for different transit nodes. Such measurement is important to evaluate the extent to which an area is oriented towards transit, but insufficient for the understanding of the heterogeneous built environment characteristics of the area around the train stations. This is because the TOD characteristics at the node level (in this paper, defined as TOD nodes) tend to be lost in the process of indicator aggregation (Singh et al., 2014). Studies have suggested that the heterogeneous built environments critically affect the implementation of TOD (Atkinson-Palombo, \& Kuby, 2011; Baker, Washington, \& Turrell, 2014), which means TOD might have different typologies according to its built environment. This implies that a general aggregated level of TOD might not be able to reflect the performance across different types of nodes in the transit network because the nodes might play different roles within the network. As a network system, there might be synergy effects between the nodes of the TOD network (Capineri \& Kamann, 1998; Meijers, 2005), such as competition, complementarity and collaboration. 
The present study develops a TOD typology for the TOD network of the Arnhem-Nijmegen region, in the Netherlands, to identify the characteristics of different nodes in the transit network. Based on this typology, we analyze complementarity effects between TOD nodes of the TOD network, discussing how the individual nodes interact. A Latent Class Cluster Method (LCCM) was used to identify TOD typologies, and Correspondence Analysis to understand potential complementary roles between the identified typologies. The paper seeks to answer three questions: (1) does the aggregated level of TOD reflect the performance across different nodes? (2) what are the roles of the nodes within the TOD network? and (3) are there complementarity effects between TOD nodes within a TOD network?

The paper is structured as follows: after this introduction, we will discuss current approaches to measuring the level of TOD within transport-land-use projects. We discuss the importance of identifying typologies amongst the nodes of a TOD network, and further define what we understand by network synergy and its related process of complementarity. The study area is presented in the third section, followed by the analysis of results. The conclusions section will elaborate on the main contributions of this paper.

\section{$2 \quad$ Literature review}

\subsection{TOD measurement}

Depending on the conditions around the different stations, the implementation of a TOD may be different. Assessing the existing TOD conditions and understanding the heterogeneity of the built environment before implementing a TOD project becomes vital to enhance the success rate of the project. A thoughtful analysis of the existing built environment can ease facilitation of a future TOD (Kamruzzaman, Baker, Washington, \& Turrell, 2014). Singh et al. (2014) share a similar opinion and argues that a scientific analysis on measuring existing TOD levels is a prerequisite that can help to uncover the extent to which an area is transit-oriented, and for what reasons. In her study, she analyses the TOD network of the city region of Arnhem-Nijmegen, in the Netherlands, by aggregating multiple spatial indicators under a SMCA framework to arrive at a general TOD level value.

However, for measuring the existing levels of TOD, having such a general value is essential but insufficient for the understanding of the heterogeneous built environment because the TOD characteristics are lost in the process of indicator aggregation. Understanding the heterogeneous built environment of TOD is important since it helps to understand why TOD projects unfold differently across the system (Atkinson-Palombo \& Kuby, 2011). Given the fact that TOD is multi-dimensional and multi-functional, with different purposes and different aims, TOD implementation can take a variety of forms and the individual node can have different roles within the network system, complementing each other (Atkinson-Palombo \& Kuby, 2011). Furthermore, there is no "one-size-fits-all" TOD mode (Austin et al., 2010) and a TOD development rarely starts from zero; needs instead to be thought up around pre-existing structures and conditions. We can thus argue that a well-performing TOD transit node does not necessarily have to be ideal in all dimensions of the conventional TOD criteria and that the various characteristics of the existing built environment could be determinant factors forming the heterogeneous typologies of TOD.

\section{$2.2 \quad$ TOD typology}

There is an emerging interest in developing a TOD typology, regarded as a tool for informing policy prescription and evaluation (Higgins \& Kanaroglou, 2016). According to (Kamruzzaman et. al., 2014), developing a typology is a way to group together areas that have a common set of characteristics. The 
authors indicate the benefit of developing a TOD typology as convenient for urban planning and design tasks and operations since within the same TOD typology nodes can share a common set of strategies; identification of the general development potentials so that once a TOD is classified, the optimal figuration can be deducted (e.g., the desirable density, mixed use); reducing the complexity of managing the infrastructure by enabling a common standard within the same TOD typology (e.g. operations); enabling the comparison within the same typology, identifying the benchmark station of a certain type which can help to assess the other stations of the same type.

Research regarding the definition of TOD typologies has been carried out since the birth of TOD. Calthorpe (1993) made a dichotomy between residential TOD and job-generating TOD. Dittmar and Poticha (2004) expanded these dichotomous typologies with the distinction between urban and suburban areas. In addition, Hancock et al., (2014) identified 5 types of TOD for strategic planning. These typologies, regarded by Higgins and Kanaroglou (2016) as the "normative TOD typologies," only generally outline the characteristics of what different TOD contexts should look like in terms of factors such as densities, housing types, and transit service. Aside from these normative typologies, research has tried to achieve a more rigorous assessment by using other approaches, which aim to reduce the complexity created by the heterogeneity in the node context.

This paper applies the Latent Class Cluster Method (LCCM) as a tool for developing a TOD typology for the Arnhem-Nijmegen region. LCCM was chosen as a superior approach when compared to hierarchical and k-means clustering methods because (1) it uses a probabilistic approach (in case of categorical variables) or means/rates (in case of continuous or count variables) to clustering methods, (2) accommodates unscaled/unstandardized variables, allowing the model outputs to be analyzed in their own units, (3) accommodates different data formats (nominal, ordinal, continuous) (Higgins \& Kanaroglou, 2016). In addition, by using maximum likelihood for parameter estimation, LCCM can produce statistics such as Bayesian Information Criterion (BIC) and entropy of the model, helping users to decide on the number of clusters. LCCM also avoids the problems commonly observed in hierarchi$\mathrm{cal}$ and $\mathrm{k}$-means clustering models in terms of the scaling of variables and its ability to accommodate unscaled or unstandardized variables.

\subsection{Network synergy}

Synergy refers to "a situation in which the effect of two or more cooperating or combined bodies or functions is larger than the sum of the effects each body or function alone can achieve" (Meijers, 2005, p. 766). The concept of a network system is highly associated with synergy effects. A network basically consists of four elements: nodes, linkages between nodes, flows, and meshes. When applied to the field of urban transport and land use, nodes can be understood as cities or stations; linkages can be seen as the roads or railways that connect the nodes; flows can refer to people with travel demands or goods to be transferred; and meshes are the undeveloped or preserved land (or hinterland) compassed by the nodes and linkages. When these elements function as a network, the nodes might function independently but it is their complementarity that generates synergy effects that contributes to a network's added value (Meijers, 2005).

For two or more nodes within a network to develop synergy effects, two preconditions must be in place: (a) "there must be differentiation in the supply of activities or places," otherwise the activities or places will be in a relationship of Competition (since they are more or less similar and mutually replaceable) instead of Complementary; (b) "the geographical markets of demand for these activities or places must at least partly overlap," which means the nodes need to share the same markets, otherwise the supplies of one cannot meet the demands of the other even if that supply could cater to that demand, i.e. if the provisions of different types of residential milieus matches the need of different preferences of 
a regional population, these provisions are complementary (Musterd \& van Zelm, 2001).

The concepts of "places" and "activities" explain where and why people reside/travel to. The supplies and demands of places and activities and the infrastructure system in place offer a way to understand the interaction between land use and transport: activities take place in geographic space (places) and stimulate travel demand. Transferring this thinking to a TOD network, the TOD nodes and their surroundings are the places, whilst activities around the nodes characterize the nodes (e.g., different land uses invite different activities) and are the reason why people travel to these nodes. In the scope of this paper, only complementarity effects will be explored because we are interested in illustrating how, by interacting with nodes that are different, a single node can hold an important role within the TOD network.

Ideally, the 5 TOD dimensions (Density, Diversity, Design, Destination accessibility and Distance to transit) would structure our analysis of complementarity in a network. However, some of these dimensions are not shareable to other nodes, meaning they do not meet the precondition of geographical markets that partly overlap. This is the case of distance to transit as the catchment area of a node will not complement the catchment area of another node. This could be taken into consideration if we were looking for competition between nodes. Another dimension that is not open for complementarity is Design, since the street connectivity or the friendly walking environment of a node will not complement those of the other nodes, because the resulting built environment tends to be exclusive. The dimensions of Density and Diversity are the ones most likely to meet the preconditions of geographical markets that partly overlap, and of differentiation in the supply and demand of activities and places. In these dimensions, the demands and supplies of one node can be partly met by those of another node. This is why these two dimensions are included in the analysis.

\section{Study area}

The Arnhem Nijmegen City Region, in the Netherlands, is located at the heart of a vast metropolitan area. The region is flanked by the Randstad conglomeration to the West, the Flemish Diamond to the South and the Ruhr to the East. With the ambition to become the second largest economic area in the Netherlands after Randstad by 2020, the city region aims to promote regional cooperation (ArnhemNijmegen City Region, 2018). It is esteemed to be one of the beacons of TOD in the Netherlands (Pojani \& Stead, 2014). It is also considered representative of other European regions of similar scale that are pursuing TOD. Therefore, the city region of Arnhem-Nijmegen was considered a suitable case study for this paper.

The city region covers more than $1000 \mathrm{~km}^{2}$ with a population of over 750,000 inhabitants. However, individually, Arnhem and Nijmegen are relatively small-size cities (respective 154,000 and 172,000 inhabitants), comparing to Amsterdam $(833,000)$ and Rotterdam $(629,000)$ (CBS, 2017). ArnhemNijmegen city region is served by a rail-based national as well as regional transit system composed of 22 train stations, as shown in Figure 1 and Figure 2. The railway connection in the region is shown in Figure 3, showing the stations that serve as main hubs within the network. 


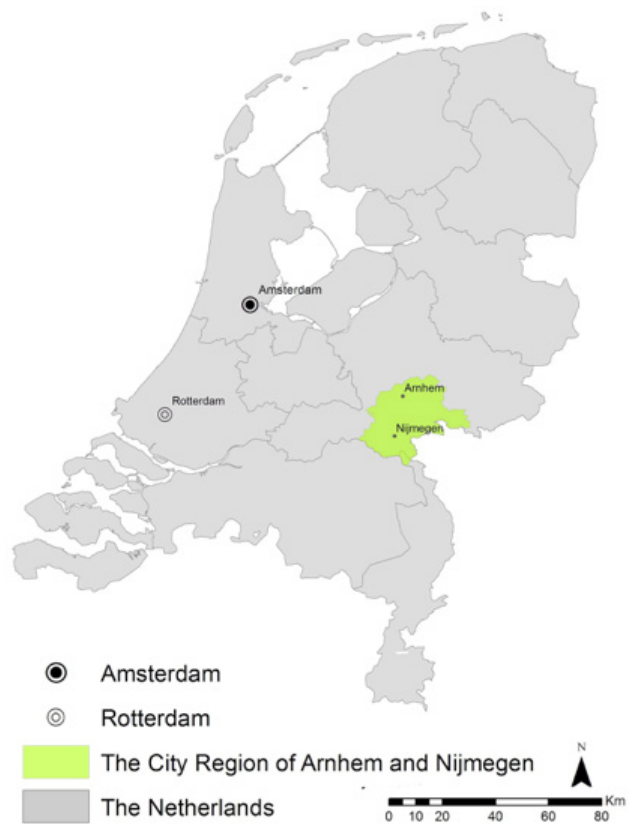

Figure 1: The Arnhem-Nijmegen region located in the Netherlands

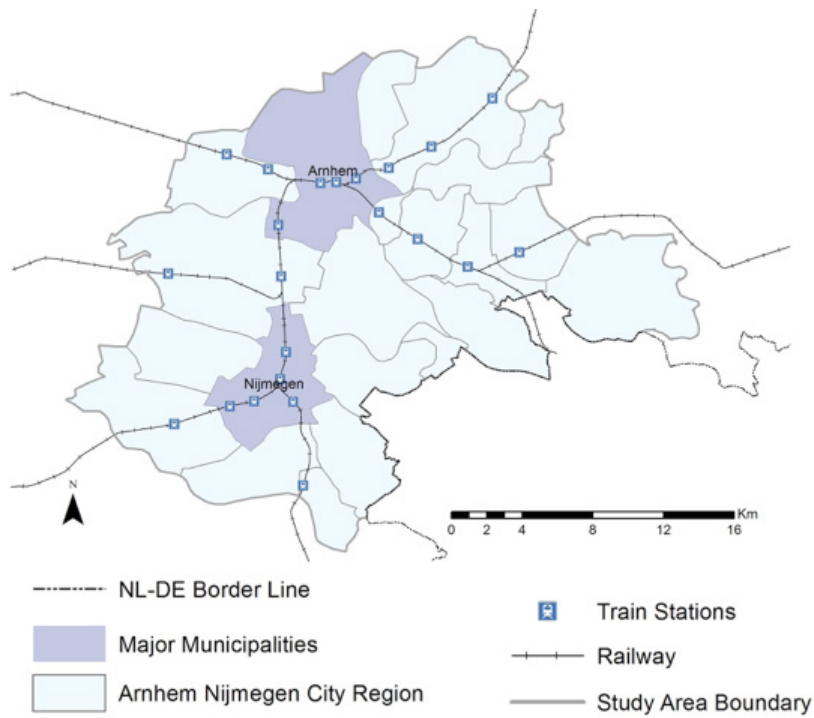

Figure 2: The TOD network of the region and its 20 train stations

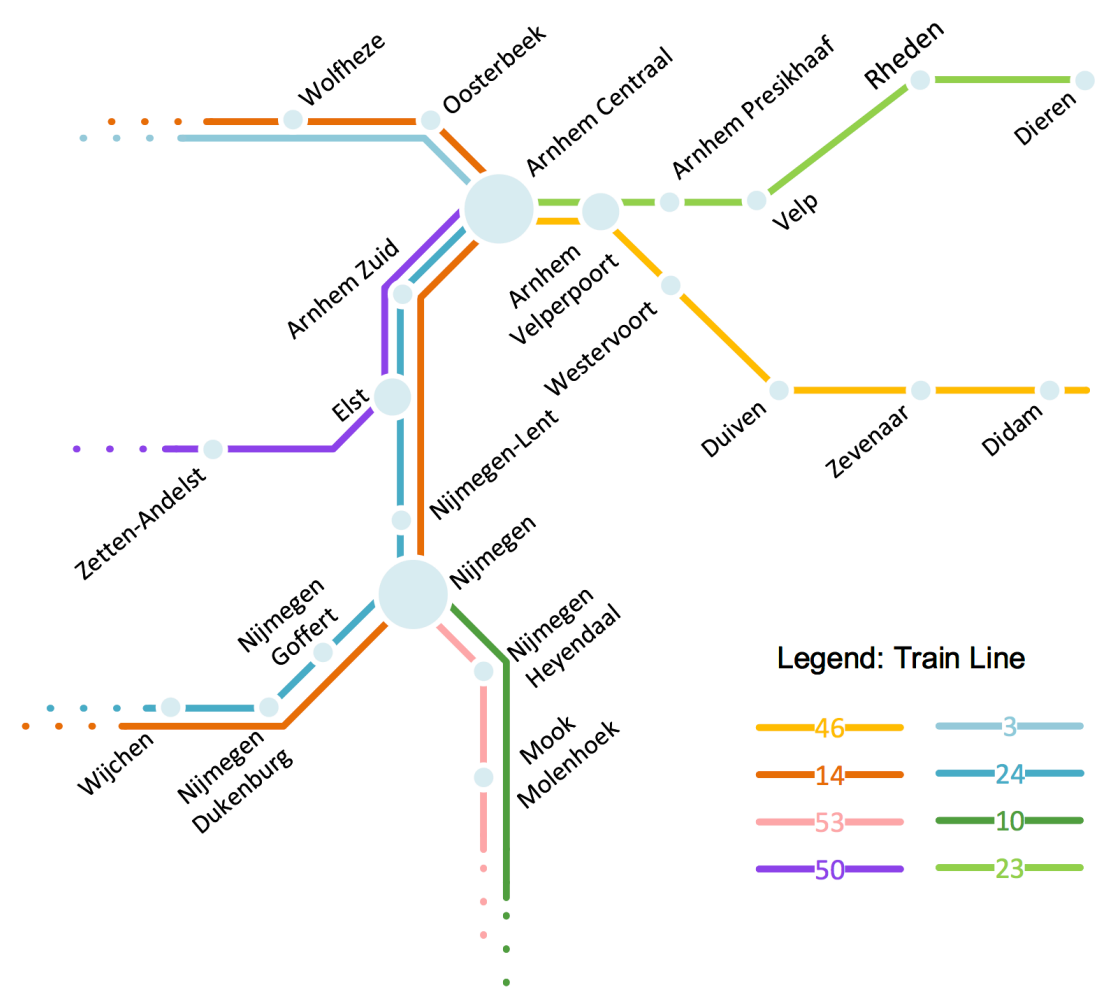

Figure 3: Railway service in the region of Arnhem-Nijmegen 


\section{$4 \quad$ Analysis and results}

\subsection{TOD measurement}

Based on the study of Guerra, Cervero, and Tischler (2013), we adopted an 800-meter buffer around the transit station as the unit of analysis. The size of the buffer simulates the catchment of people walking to/from the station along the pedestrian network within 10 minutes. Figure 4 illustrates the buffers around 3 train stations in Arnhem.

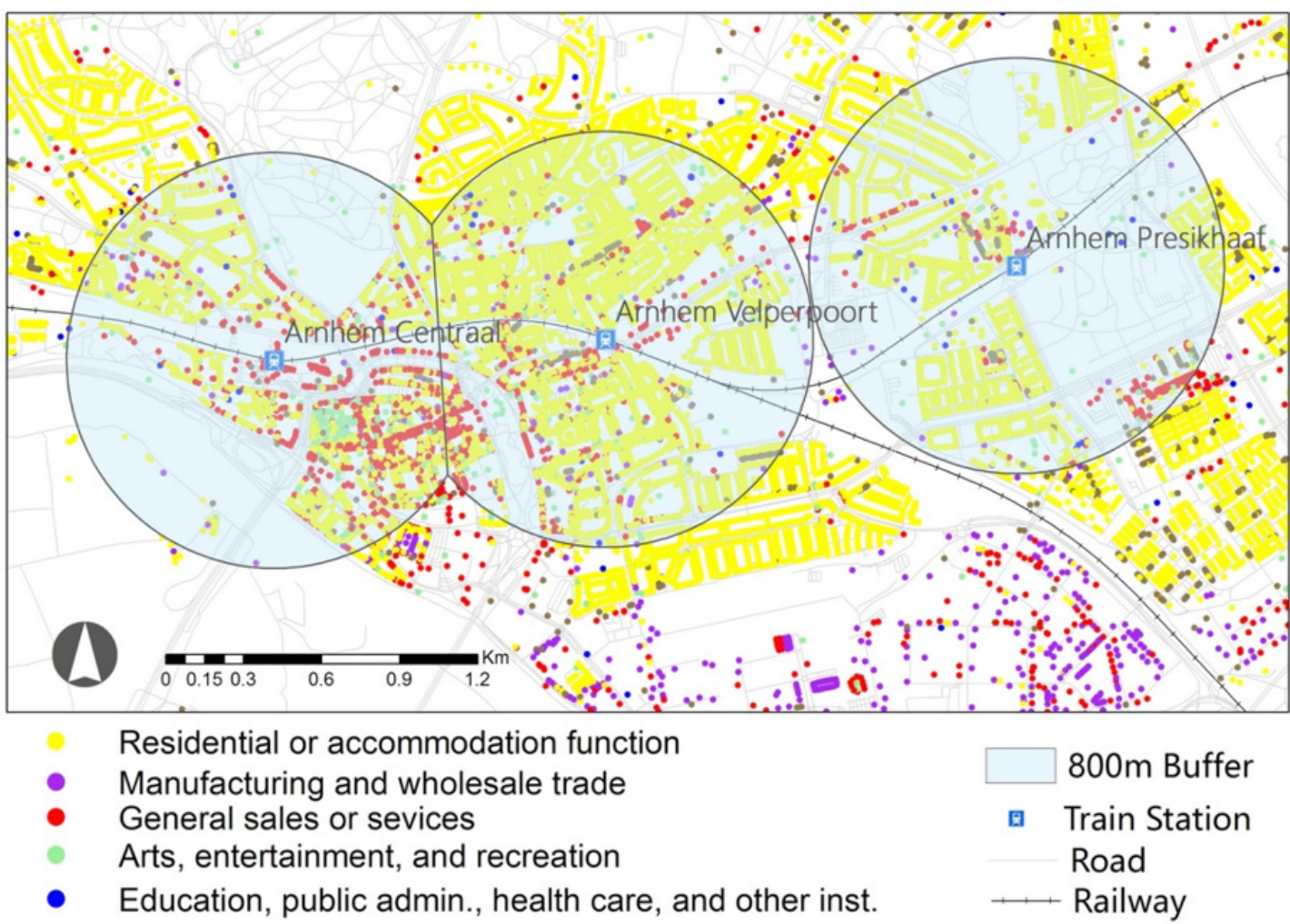

Figure 4: Buffer areas of 800 meters for three train stations in Arnhem

The indicators selected for this study are quantitative, derived from the 5Ds of the built environment indicators (Ewing \& Cervero, 2001, 2010). However, our study only considers 4Ds indicators (density, diversity, destination accessibility and design). Distance to transit was not considered because the station areas were defined by distance to transit ( 800 meters, or around 10 -minute walk) therefore all stations would perform similarly in regard to this indicator. The measurement variables for the indicators and the corresponding data source are presented in Table 1. 
Table 1: TOD indicators and measurement variables

\begin{tabular}{|l|l|l|}
\hline Indicator & Measurement variables & Data source \\
\hline \multirow{2}{*}{ Density } & Population Density & Dutch Statistics Office (CBS) \\
\cline { 2 - 3 } & Job density & $\begin{array}{l}\text { Provincial Employment Survey, 2015 (Prov- } \\
\text { ince of Gelderland) }\end{array}$ \\
\cline { 2 - 3 } & Business Density & $\begin{array}{l}\text { Dutch Cadastral Office - Basisregistratie Ad- } \\
\text { ressen en Gebouwen (BAG) }\end{array}$ \\
\hline Diversity & Land Use Diversity & (BAG) \\
\hline Destination Accessibility & Mixed-ness of Land Uses & (BAG) \\
\hline Design & Intersection Density & (BAG) \\
\cline { 2 - 3 } & Length of Bicycle and Pedestrian Networks & Dutch Cyclist Union (Fietsersbond) \\
\hline
\end{tabular}

Density was expressed using three measurement variables: population, job and business density. All variables were calculated for the buffer area (800 meters), and reflect the density per $\mathrm{Km}^{2}$, i.e., population density includes the number of residents living within an 800-meter buffer area, around each of the 20 train stations. Job density includes the number of jobs in 21 different sectors, in the buffer area, and was used to reflect the intensity of employment that brings commuters to the buffer area. Business density includes industrial, shops and offices facilities, and is used to reflect the variety of business-related land uses, an essential characteristic of the TOD area.

The local destination accessibility was measured with the land use mixed-ness index, which indicates the easiness to access resources within short trips. It is calculated with a formula adapted from (Zhang \& Guindon, 2006):

$\operatorname{MI}(\mathrm{i})=\frac{\left(\sum_{\mathrm{j}} \mathrm{L}_{\mathrm{o}}\right)}{\left(\sum_{\mathrm{j}}\left(\mathrm{L}_{\mathrm{r}}+\mathrm{L}_{\mathrm{o}}\right)\right.}$

where $\mathrm{MI}(\mathrm{i})$ is the mixed-ness index of buffer area $\mathrm{i}, \mathrm{L} \_\mathrm{r}$ and $\mathrm{L} \_\mathrm{o}$ are respectively residential land uses and non-residential land uses. The proportion of non-residential land uses within a small calculation area is calculated for each residential point $\mathrm{j}$. The value of $\mathrm{MI}(\mathrm{i})$ shows a balanced mixed-ness when it is 0.5 . When the index is closer to 0 or 1 , the more biased it is to the respective land use.

Land use Diversity was measured with the widely used "entropy" concept. High land use diversity is indicated by a high value of entropy, thus, higher levels of TOD-ness. This indicator was applied to the Dutch spatial planning context by Ritsema van Eck and Koomen (2008) and adapted by Singh et al. (2014) as follows:

$\mathrm{LU}_{\mathrm{d}}(\mathrm{i})=\frac{-\sum_{\mathrm{i}} \mathrm{Q}_{\text {lui }} \times \ln \left(\mathrm{U}_{\text {lui }}\right)}{\ln (\mathrm{n})}$

where,

$\mathrm{Q}_{\text {lui }}=\frac{\mathrm{S}_{\text {lui }}}{\mathrm{S}_{\mathrm{i}}}$

$\mathrm{LU}_{\mathrm{i}}=$ Land use class within the buffer area $i$

$\mathrm{Q}_{\mathrm{lui}}=$ The share of specific land use within the buffer area $i$

$\mathrm{S}_{\text {lui }}=$ Total area of the specific land use within the buffer area $i$

$\mathrm{S}_{\mathrm{i}}=$ Total area of buffer $i$ 
As for the Design aspect, the total length of pedestrian and bicycle lanes was taken as a measure that reflects the length of accessible roads for non-motorized transport. Intersection density is a commonly adopted indicator in this context. It was calculated to measure the street connectivity of the road network of each station area. The hypothesis is that the higher the intersection density, the better for cyclists and pedestrians as the routes may become shorter in terms of travel distance (Ewing \& Cervero, 2001). One could also argue that the higher intersection density might increase travel times because of the time spent on waiting at crossings. Generally, people would choose the shortest route if they are familiar with the environment. So, we argue that intersection density can be an indicator to measure "distance to transit," however, may not be "time to transit."

Subsequently, each measurement variable was quantified using ArcGIS. To enable the comparison of the TOD level between the nodes, the indicators were first standardized using unit-based normalization method, and then aggregated into a TOD index with an equal-weighted method. Correlations between the variables were examined (Pearson's), and results do show some high and significant correlation between the variables (Table 2). There are high and significant correlations between the density variables, and between the diversity variables, as expected. A high job density is associated with a high business density, for example, and a high mixed-ness of land uses is associated with land-use diversity. Nevertheless, the high correlation between some variables was not considered problematic as, according to a fundamental assumption of latent class analysis, the "local independence," input indicators can be highly correlated while output classes are conditionally independent of each other, which means they are not correlated within the class (Masyn, 2013).

Table 2: Correlation matrix of the TOD variables

\begin{tabular}{|l|l|l|l|l|l|l|l|}
\hline & $\begin{array}{l}\text { Population } \\
\text { Density }\end{array}$ & Job Density & $\begin{array}{l}\text { Business } \\
\text { Density }\end{array}$ & $\begin{array}{l}\text { Intersection } \\
\text { Density }\end{array}$ & $\begin{array}{l}\text { Land Use } \\
\text { Diversity }\end{array}$ & $\begin{array}{l}\text { Mixed-ness } \\
\text { of Land Uses }\end{array}$ & $\begin{array}{l}\text { Length Bicycle + } \\
\text { Pedestrian Network }\end{array}$ \\
\hline Population Density & 1 & $.677^{* *}$ & $.742^{* *}$ & $.753^{* *}$ & -.059 & -.218 & $.804^{* *}$ \\
\hline Job Density & $.677^{* *}$ & 1 & $.749^{* *}$ & $.440^{*}$ & .193 & -.011 & $.529^{* *}$ \\
\hline Business Density & $.742^{* *}$ & $.749^{* *}$ & 1 & .420 & .409 & .162 & $.545^{* *}$ \\
\hline Intersection Density & $.753^{* *}$ & $.440^{*}$ & .420 & 1 & -.313 & $-.456^{*}$ & $.882^{* *}$ \\
\hline Land Use Diversity & -.059 & .193 & .409 & -.313 & 1 & $.695^{* *}$ & -.222 \\
\hline Mixed-ness of Land Uses & -.218 & -.011 & .162 & $-.456^{*}$ & $.695^{* *}$ & 1 & -.372 \\
\hline $\begin{array}{l}\text { Length of Bicycle and } \\
\text { Pedestrian Networks }\end{array}$ & $.804^{* *}$ & $.529^{* *}$ & $.545^{* *}$ & $.882^{* *}$ & -.222 & -.372 & 1 \\
\hline
\end{tabular}

*; ** Correlation is significant at the 0.05 ; 0.01 level (2-tailed)

\subsection{TOD typology}

This study applies the Latent Class Cluster Method (LCCM) as a tool for developing a TOD typology for the Arnhem-Nijmegen region. The quantified 4D indicators were input to the software LatentGold (version 5.1) where the LCCM was estimated. Two output statistics were analyzed in order to select the number of classes: the BIC value and the entropy value. The BIC statistic is a complement to model fit, and takes into account the parsimony (degrees of freedom or number of parameters) of the model. Entropy indicates how well the model predicts class memberships. The closer these values are to 1 the better the prediction.

In Figure 5, the model fit statistics of the LCCM are shown. To demonstrate the class selection, the distribution of BIC and Entropy are presented across different classes. The model was estimated from 2 to 7 classes. The selected number of classes was the one with the lowest BIC value, followed by the highest Entropy value. The model with 3 classes was selected as a better solution for the class division. 


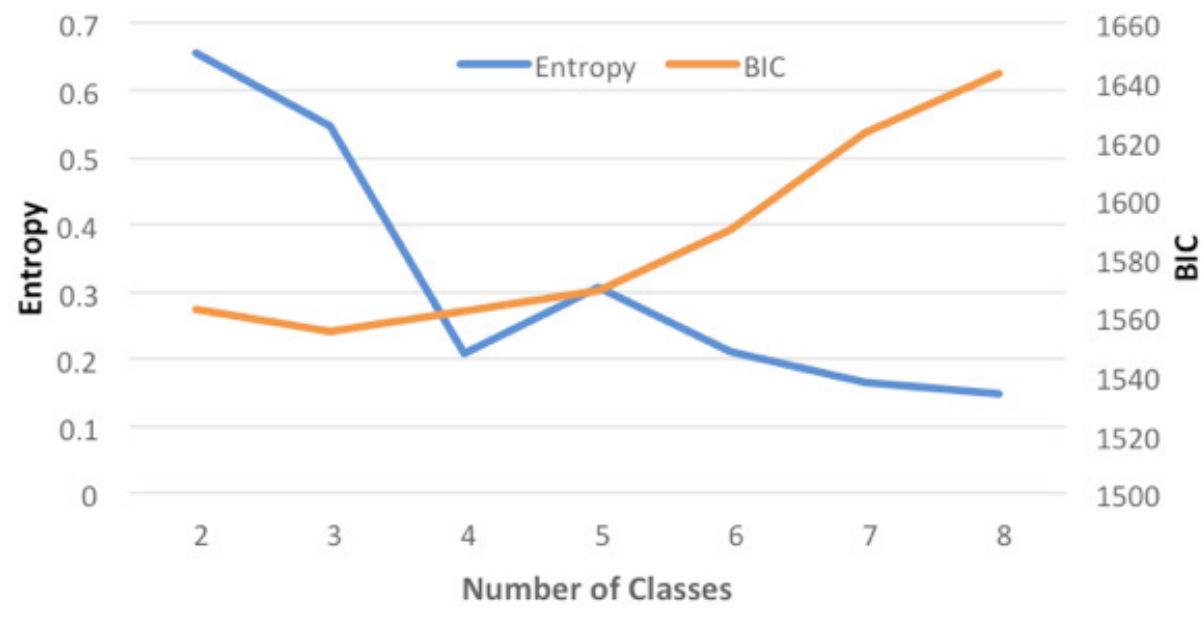

Figure 5: Latent class model fit statistics

Table 3 presents the model results of the LCCM. Model coefficients indicate each class's mean value for each TOD indicator, and associated statistical test. The percentages in parentheses correspond to each cluster's deviation in percentage terms from the sample mean. LCCM's do not require variable transformation, therefore the model outputs are interpreted based on the original units of each variable. The LCCM clustered 22 train stations of the Arnhem-Nijmegen region into three TOD typologies. Based on the characteristics of the typologies, names are given to stations to enable the recognition and discussion: Suburban Residential, Urban Residential and Urban Mixed Core (Figure 6).

The Suburban Residential class contains 10 stations, illustrated in yellow in Figure 6. It is characterized by low population density ( $147 \%$ smaller than the sample mean) and low job and business density (respectively $271 \%$ and $347 \%$ smaller than the sample mean). These stations also feature lower-thanaverage intersection density (a measure for street connectivity) and length of bicycle and pedestrian networks. These nodes are predominantly residential, and located farther away from employment centers. They might be, however, important as trip origins. For instance, station 4 (Zevenaar) ranks low in aggregated level of TOD and the node population density is relatively low (Figure 7). However, it has a relatively high transit ridership, which accounts for its important role within the TOD network as a feeder station. This means that the aggregated level of TOD does not necessarily capture the significance of this station for the TOD network.

The second typology was labeled as Urban Residential and it is characterized by lower destination accessibility (39\% smaller than the mean) and lower diversity of land uses ( $25 \%$ smaller than the mean) (Table 3). However, it has more job opportunities when compared to the suburban residential class. The design indicator scores higher for this class, meaning that the street design around the station is more suitable for cyclists and pedestrians. Seven stations were classified in this typology and Station 21 is taken as illustration (Figure 8).

The Urban Mixed Core class contains the three most urban stations, with all estimated indicators higher than the sample mean (Table 3). These features are characteristic of central business districts and indeed this is where these three stations are located. Station 1 is used to exemplify this station type (Figure 9). 
Table 3: Latent class cluster model of TOD nodes

\begin{tabular}{|c|c|c|c|c|c|c|}
\hline Indicator & $\begin{array}{c}\text { Measurement } \\
\text { variables }\end{array}$ & $\begin{array}{c}1 . \\
\text { Suburban } \\
\text { Residential } \\
\end{array}$ & $\begin{array}{c}2 . \\
\text { Urban Resi- } \\
\text { dential } \\
\end{array}$ & $\begin{array}{c}3 . \\
\text { Urban Mixed } \\
\text { Core }\end{array}$ & p-value & $\mathbf{R}^{2}$ \\
\hline \multirow[t]{3}{*}{ Density } & $\begin{array}{l}\text { Population } \\
\text { Density }\end{array}$ & $\begin{array}{l}-2693.39 \\
(-147 \%)\end{array}$ & $\begin{array}{r}-578.49 \\
(-15 \%)\end{array}$ & $\begin{array}{c}3271.89 \\
(42 \%)\end{array}$ & 0 & .74 \\
\hline & Job Density & $\begin{array}{l}-3287.35 \\
(-271 \%)\end{array}$ & $\begin{array}{l}-727.15 \\
(-19 \%) \\
\end{array}$ & $\begin{array}{c}4014.49 \\
(47 \%) \\
\end{array}$ & 0 & .67 \\
\hline & $\begin{array}{l}\text { Business } \\
\text { Density }\end{array}$ & $\begin{array}{l}-162.59 \\
(-347 \%)\end{array}$ & $\begin{array}{l}-128.59 \\
(-159 \%)\end{array}$ & $\begin{array}{l}291.19 \\
(58 \%) \\
\end{array}$ & 0 & .89 \\
\hline Diversity & $\begin{array}{l}\text { Land Use } \\
\text { Diversity }\end{array}$ & $\begin{array}{l}-.001 \\
(.4 \%)\end{array}$ & $\begin{array}{c}-.052 \\
(-25 \%)\end{array}$ & $\begin{array}{c}.054 \\
(17 \%)\end{array}$ & .055 & .17 \\
\hline $\begin{array}{l}\text { Destination } \\
\text { accessibility }\end{array}$ & $\begin{array}{c}\text { Mixed-ness of } \\
\text { Land Uses }\end{array}$ & $\begin{array}{c}.016 \\
(10 \%) \\
\end{array}$ & $\begin{array}{c}-.04 \\
(-39 \%) \\
\end{array}$ & $\begin{array}{c}.024 \\
(15 \%) \\
\end{array}$ & .067 & .15 \\
\hline \multirow[t]{2}{*}{ Design } & $\begin{array}{c}\text { Intersection } \\
\text { Density }\end{array}$ & $\begin{array}{l}-43,83 \\
(-44 \%) \\
\end{array}$ & $\begin{array}{l}18.94 \\
(12 \%) \\
\end{array}$ & $\begin{array}{l}24.89 \\
(15 \%) \\
\end{array}$ & 0 & .59 \\
\hline & $\begin{array}{c}\text { Length Bicycle } \\
+ \text { Pedestrian } \\
\text { Network }\end{array}$ & $\begin{array}{c}-14816.51 \\
(-43 \%)\end{array}$ & $\begin{array}{c}4624.94 \\
(9 \%)\end{array}$ & $\begin{array}{c}10191.57 \\
(17 \%)\end{array}$ & 0 & .71 \\
\hline
\end{tabular}

Percentage between parentheses corresponds to each class deviation from the sample mean.

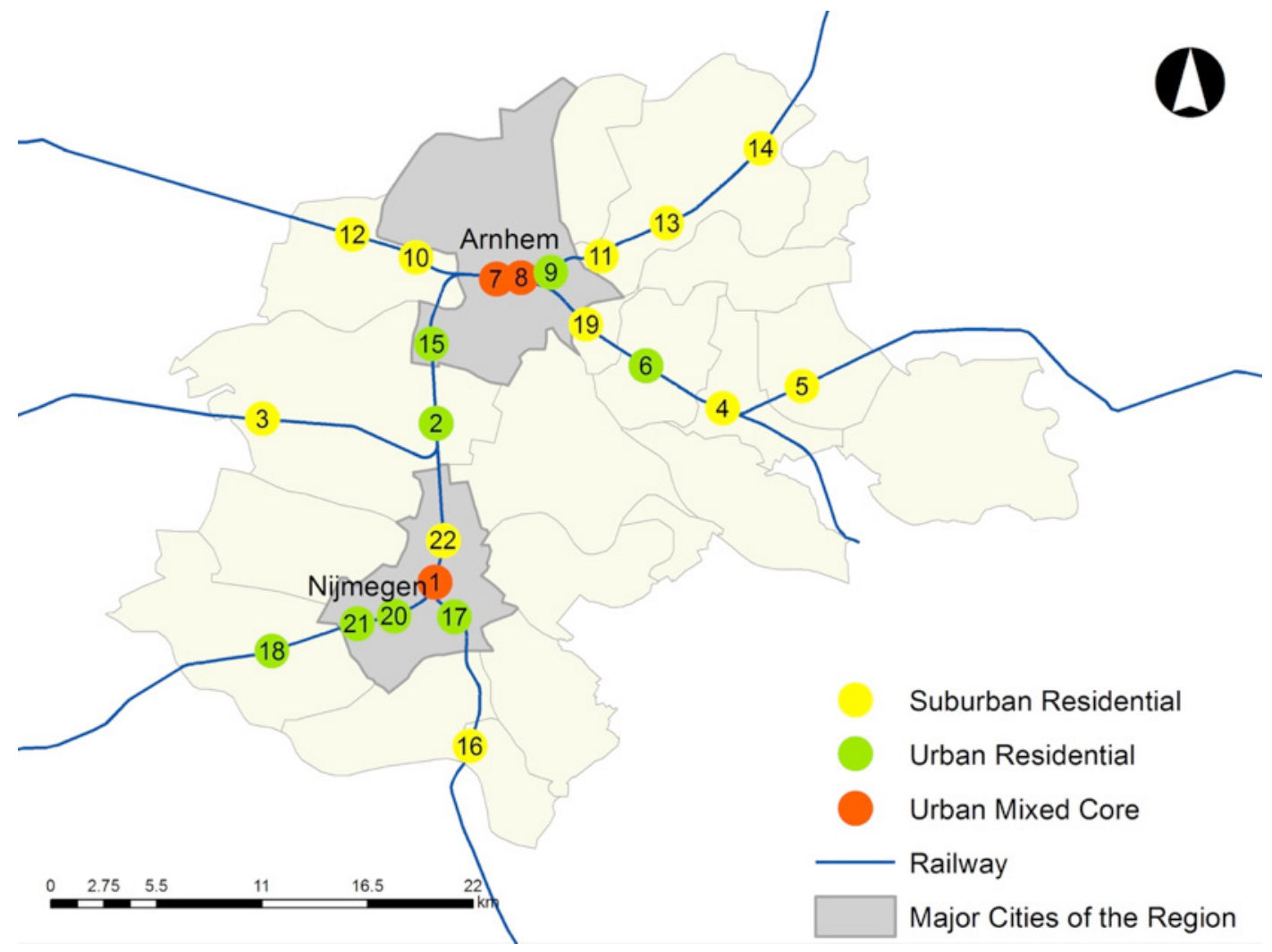

Figure 6: Typology of the TOD network of the region of Arnhem-Nijmegen 


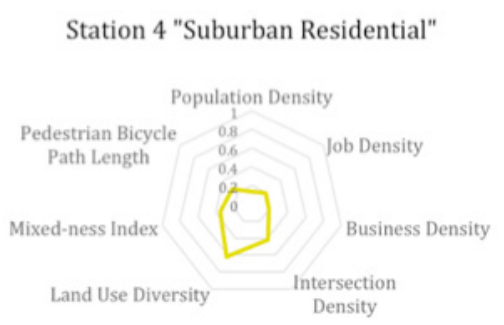

Figure 7: TOD characteristics of station 4 "suburban residential"
Station 21 "Urban Residential"

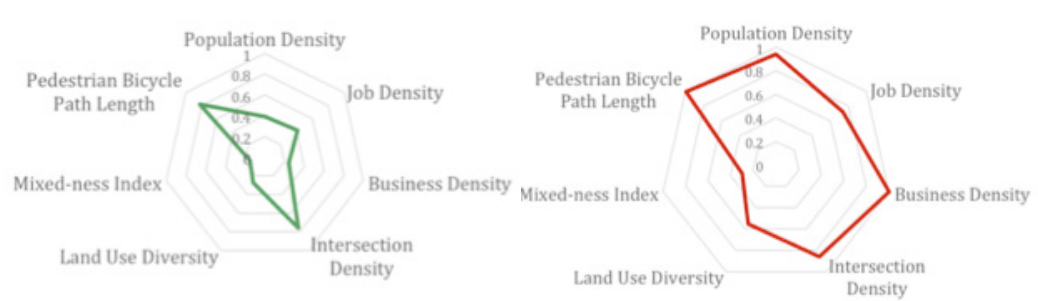

Figure 8: TOD characteristics of station 21 "urban residential"
Figure 9: TOD characteristics of station 1 "urban mixed core"

Some unexpected classifications were encountered for some stations. For instance, station 6 was hypothesized as a suburban residential instead of urban residential. This can be explained by the location of the station within the urban fabric. Figure 10 shows that station 6 is located right in the middle of the town, while station 19 is located at the edge of the town.

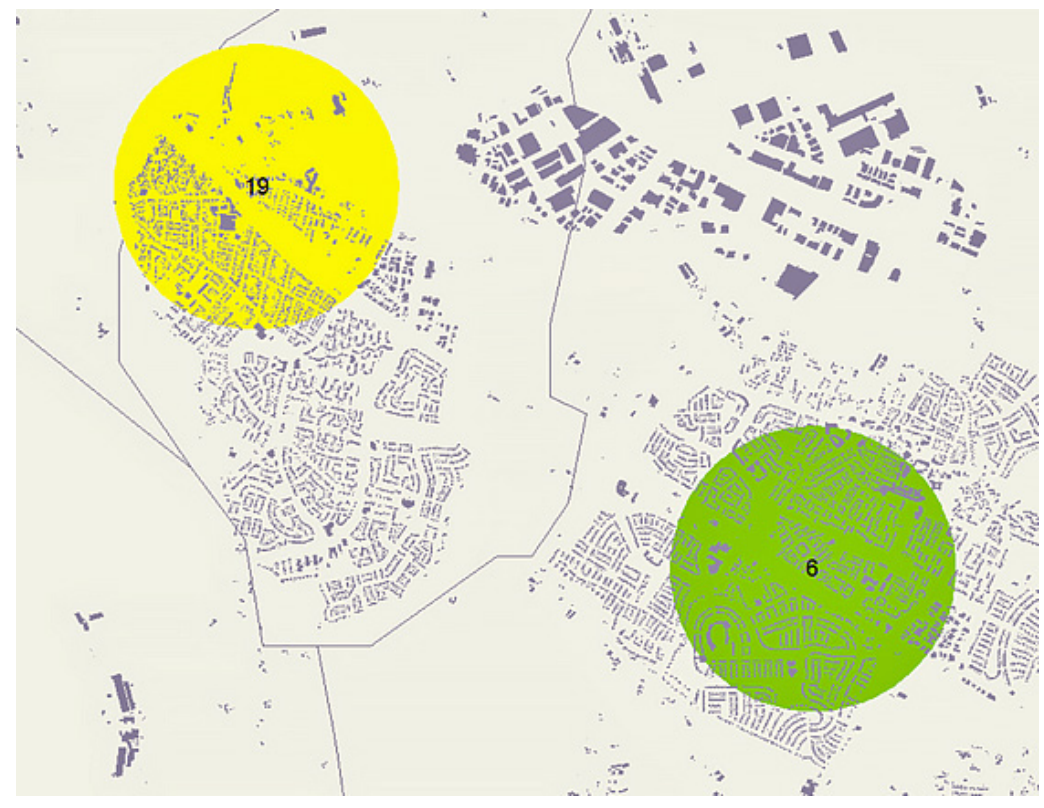

Figure 10: Locations of stations 6 and 19 within the urban fabric

In an attempt to validate the TOD typology, Table 4 discusses the relationship between the ridership of each station (passenger count) with its aggregated level of TOD. The assumption is that high ridership would positively correlate with aggregated level of TOD because one of the objectives of TOD is to dissuade travelers from taking the automobile. However, by looking at the difference between passenger count rank and TOD-ness rank, we can explain characteristics of the different stations by highlighting variables other than trip generators, namely job density, diversity of usage, etc. The passenger count is a good predictor for aggregated level of TOD, but it is not the only one, therefore it was used in this analysis as a control variable. For example, station 8 ranks 8 th in relation to passenger count, but ranks 3rd in aggregated level of TOD. It is located in the inner city, with the university and the hospital in its surroundings, generating a lot of employment opportunities. The difference in rank may be 
explained by the power of attraction of this station as an important business center, whereas passenger counts are associated with origins of trips. Also, since this station is close to Arnhem central, which has a higher train frequency, a lot of people cycle directly to this station, thus causing lower passenger counts in station 8. The opposite is observed when analyzing the differences in rank of station 4 (3rd in passenger count and 12th in aggregated level of TOD). This station is characterized mainly as a feeder station, performing low within the built-form indicators.

Due to data unavailability, only the data about passenger count was used to validate the typology; however other measures can be used, namely commute mode share and travel characteristics. Ideally, information about inbound and outbound stations, i.e., the station origin-destination information (the O-D pair of the train trip), would allow the identification of station correlations. However, the Dutch train service provider does not make such information readily available.

Table 4: Validation of the typology in relation to passenger count information

\begin{tabular}{|c|c|c|c|c|c|c|}
\hline ID & Typology & TOD level & $\begin{array}{c}\text { TOD level } \\
\text { rank }\end{array}$ & $\begin{array}{c}\text { Passenger } \\
\text { Count* }\end{array}$ & $\begin{array}{c}\text { Passenger } \\
\text { Count rank }\end{array}$ & $\begin{array}{c}\text { Difference in } \\
\text { Rank }\end{array}$ \\
\hline 1 & 3 (Urban Mixed Core) & 0.77 & 1 & 43149 & 1 & 0 \\
\hline 7 & 3 (Urban Mixed Core) & 0.73 & 2 & 38442 & 2 & 0 \\
\hline 8 & 3 (Urban Mixed Core) & 0.72 & 3 & 3672 & 8 & -5 \\
\hline 18 & 2 (Urban Residential) & 0.47 & 4 & 4214 & 4 & 0 \\
\hline 17 & 2 (Urban Residential) & 0.45 & 5 & 3287 & 9 & -4 \\
\hline 21 & 2 (Urban Residential) & 0.44 & 6 & 2151 & 13 & -7 \\
\hline 9 & 2 (Urban Residential) & 0.43 & 7 & 3162 & 10 & -3 \\
\hline 20 & 2 (Urban Residential) & 0.39 & 9 & 1000 & 17 & -8 \\
\hline 2 & 2 (Urban Residential) & 0.39 & 10 & 3863 & 6 & 4 \\
\hline 6 & 2 (Urban Residential) & 0.37 & 11 & 3865 & 5 & 6 \\
\hline 15 & 2 (Urban Residential) & 0.29 & 14 & 2790 & 11 & 3 \\
\hline 11 & 1 (Suburban Residential) & 0.41 & 8 & 1625 & 15 & -7 \\
\hline 4 & 1 (Suburban Residential) & 0.31 & 12 & 4652 & 3 & 9 \\
\hline 16 & 1 (Suburban Residential) & 0.30 & 13 & 1224 & 16 & -3 \\
\hline 14 & 1 (Suburban Residential) & 0.29 & 15 & 3848 & 7 & 8 \\
\hline 5 & 1 (Suburban Residential) & 0.28 & 16 & 1899 & 14 & 2 \\
\hline 3 & 1 (Suburban Residential) & 0.27 & 17 & 732 & 20 & -3 \\
\hline 19 & 1 (Suburban Residential) & 0.23 & 18 & 2250 & 12 & 6 \\
\hline 10 & 1 (Suburban Residential) & 0.22 & 19 & 482 & 22 & -3 \\
\hline 13 & 1 (Suburban Residential) & 0.17 & 20 & 907 & 19 & 1 \\
\hline 12 & 1 (Suburban Residential) & 0.16 & 21 & 542 & 21 & 0 \\
\hline 22 & 1 (Suburban Residential) & 0.13 & 22 & 925 & 18 & 4 \\
\hline
\end{tabular}

*Passenger count data (from 2014) was supplied from the Dutch train service provider (Nederlandse Spoorwegen) and refers to an average working day, excluding transfers.

\subsection{Complementarity in a TOD network}

Correspondence analysis (CA) was used as a tool to measure the differentiation among the TOD typology. It is an analysis that aims to visualize the nature of correlations between the column and the row of the contingency table. The analysis was conducted with IBM SPSS Statistics (version 24). The final visualization result of CA is a map with two axes, in which the positions of the points (representing the categories) reveal the correlations between the points. Categories with similar distributions will be graphically represented by closely located points, while points further apart from each other will represent low correlation. 
Based on the developed typology, this section presents the results of the identified complementarities of the TOD network in Arnhem-Nijmegen City Region by using the data of "TOD node typologies vs. residential housing price" and "TOD node typologies vs. building uses" in the correspondence analysis. Many other relations could be explored, for example, job type or house type differentiation among the nodes. However, only Residential Housing Price (RHP) and Building Use (BU) were selected based on data availability. Residential Housing Price is used as a proxy for the supply of housing in different price ranges that exist within the TOD region. Building uses is used as a proxy for land-use differentiation within the region served by this TOD network.

\subsubsection{TOD node typologies vs. residential housing price}

The data on residential housing price was acquired from the Dutch Statistics Office (CBS). It provides information on housing price aggregated at the neighborhood level. Since the analyzing units in this study are the 800-meter buffers around the stations, the neighborhoods that are spatially intersected with a station buffer were assigned to the buffer. The values in the dataset are the averaged values at neighborhood level. The price levels used in correspondence analysis are normalized, based on the neighborhood housing prices in the whole region, to three classes, "high," "medium" and "low."

As shown in Table 5, the inertia values are far lower than 1, indicating no utterly exclusive association between the TOD node typologies and the RHP. However, the inertia of Urban Mixed Core (0.056) is significantly higher than the other two (0.022 and 0.01), indicating a higher diversity of the residential housing price in the Urban Mixed Core nodes. This means that within the nodes, Urban Mixed Core nodes provide more choices in terms of residential housing price.

Figure 11 suggests the association between different types of TOD nodes and different levels of RHP. In the graph, the origin $(0,0)$ is the mean profile of the three TOD node typologies. The origin can also be understood as the theoretical probability wherein the node typologies are independent from levels of RHP. If two node typologies lie close together, then their RHP profile is more homogeneous, whilst the further they are away, the more heterogeneous. The same condition applies to the RHP: the closer the points of RHP levels lie, the more similar the levels of RHP are distributed between the node typologies.

In this light, the point of medium RHP lying very close to the point of the suburban residential node typology indicates the suburban residential nodes are characterized by the medium-priced residential housing. The urban mixed core typology is closer to the low-price residential housing, whereas, the three node typologies are all not highly associated with high-price residential housing. These can be understood as follows: (1) since it is the housing price not the land price, the average house size in the urban mixed core nodes might be smaller than the other two typologies, given the prominently higher population density within the urban mixed core nodes (as shown in section 4.2, Table 3). An assumption could be that in the urban mixed core nodes, there are more multi-story apartments, lowering the average housing price in the nodes. With proper data (e.g., the housing type), such an assumption can be tested; (2) the urban/ suburban residential nodes consist of less low-priced house and more mediumpriced house. (1) and (2) indicate the differentiation in the provision of different level of housing among the three node typologies, therefore, suggests the complementarity among the three node typologies in terms of housing price and that people with different preferences for housing can have more choices within the network than confined to one node area alone.

It is important to note that since the data used in the analysis is at neighborhood level (the prices are the averaged housing values of the neighborhoods, not the prices of every single house), the result of $\mathrm{CA}$ in residential housing prices differentiation may not exactly reflect the most accurate extent of the correlation between the node typologies and the housing price levels. However, it still allowed capturing the general correlation between housing prices and the TOD typology developed here. 
Table 5: Inertia value for the CA of TOD node typologies vs. residential housing price

\begin{tabular}{lc}
\hline Station Type & Inertia \\
\hline Suburban Residential & 0.022 \\
Urban Residential & 0.01 \\
Urban Mixed Core & 0.056 \\
\hline Total & 0.087 \\
\hline
\end{tabular}

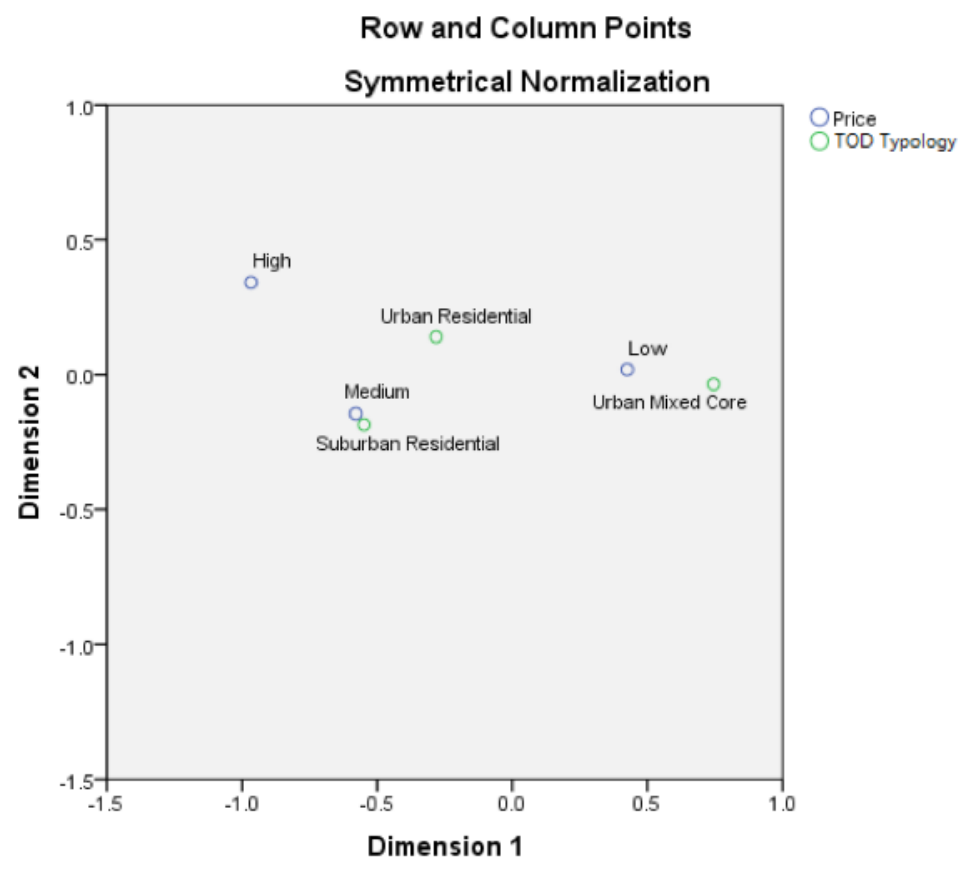

Figure 11: TOD node typologies associated with residential housing price

\subsubsection{TOD node typologies vs. building uses}

Compared to 4.3.1, the inertia of TOD node typologies vs. building uses, shown in Table 6, is relatively lower, which indicates that the building uses among the three node typologies are relatively closer to the mean profile, whereas the urban mixed core nodes still have the highest inertia indicating the highest building use diversity. This is consistent with the LCCM results, shown previously in Table 3.

The visualization of TOD node typologies associated with building use in CA is shown in Figure 12 and some patterns can be observed. First, the spread-out points can be explicitly grouped into 3 categories according to the node typologies, indicating strong building use differentiation among the three typologies. Compared to the other two, the urban mixed core typology is much closer to the building use points of office, social, commercial, logistic and industrial, which indicates, as expected, a relatively dominant position of this typology in these business and commercial activities. Second, the residential use is the closest to the origin $(0,0)$, meaning the three node typologies have similar proportion of residential building, albeit the residential point is relative closer to urban residential, confirming that urban residential have higher residential proportion. Third, sport uses are closer to suburban residential typology, which implies that suburban nodes have larger tract of land to provide for sporting 
ground. Additionally, health care use should also be noticed, that it is relatively further away from the urban mixed cored nodes in the result graph, indicating more health care facilities are located around residential type nodes.

The distinct differentiation of building uses among the nodes strongly indicates and confirms different roles of the different TOD node types in terms of the provision of activities and indicating the diversity of land uses. Therefore, within the TOD network, complementarity in the supply of activities and land uses is ensured.

Table 6: Inertia values for the CA of TOD node typologies vs. building uses

\begin{tabular}{lc}
\hline Station Type & Inertia \\
\hline Suburban Residential & 0.011 \\
Urban Residential & 0.007 \\
Urban Mixed Core & 0.017 \\
\hline Total & 0.034 \\
\hline
\end{tabular}

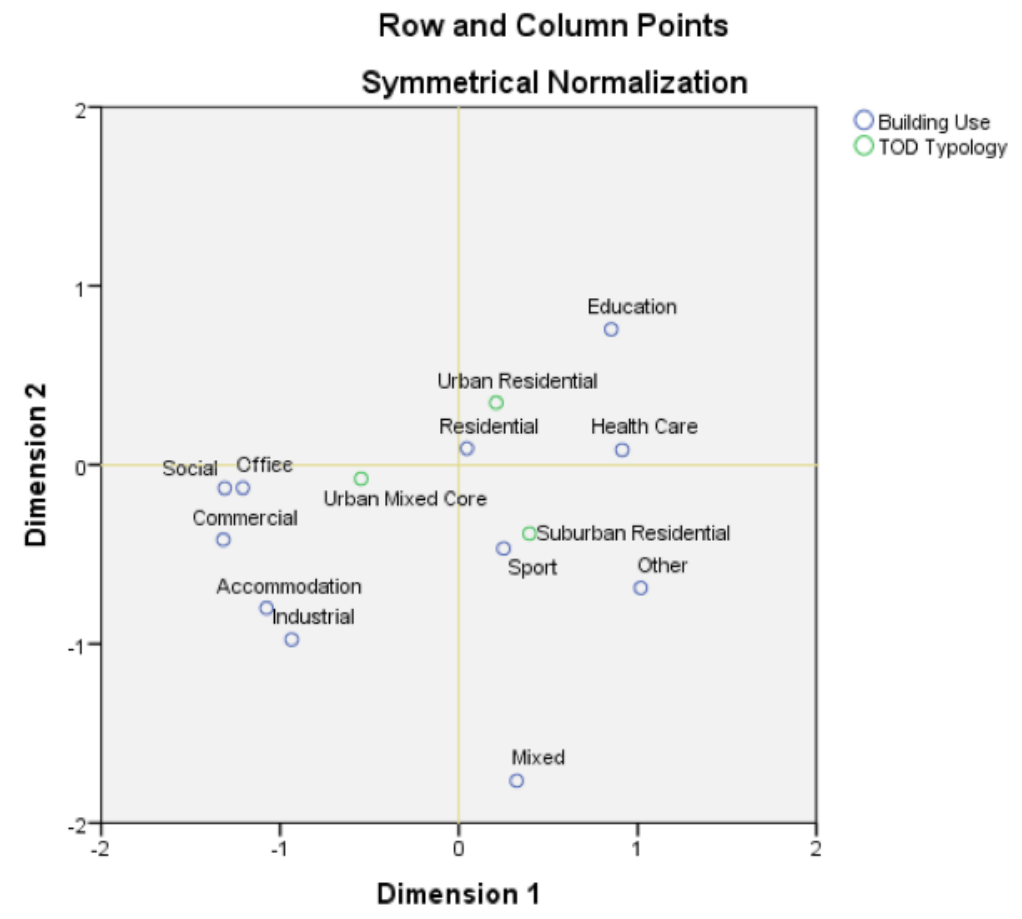

Figure 12: TOD node typologies associated with building use

\section{Conclusions}

In this paper, a TOD typology was developed to identify the characteristics of different nodes in the TOD network. Based on the developed typology, complementarity effects between TOD nodes were analyzed to understand how their effects contribute to the large-scale TOD network. Three main questions were addressed: (1) does the aggregated level of TOD reflects the performance across different nodes? (2) what are the roles of the nodes within the TOD network? and (3) are there complementarity effects between TOD nodes within a TOD network?

The measurement of TOD level at the nodes in the Arnhem-Nijmegen City Region was based on 
$4 \mathrm{D}$ built-environment dimensions. The results of the analyses indicated variation in the aggregated level of TOD among the nodes, similarly demonstrated by Singh et al. (2014). However, when the aggregated level of TOD was compared to station ridership, some stations show contradictions in the rankings, as stations that rank low in the aggregated level of TOD can still have good performance in terms of ridership. This ranking difference supports the first claim of the research that a general aggregated level of TOD might not be able to reflect the performance of every node. It also indicates that the nodes might not need to perform well in all the dimensions of TOD.

The above indication leads to the second research question addressed here, which was to investigate the roles of the nodes within the TOD network. A Latent Class Clustering Method (LCCM) was conducted to develop typologies for TOD nodes. Three typologies were identified. The reason might be that the network is relatively small and dominated by two very strong core stations, which influence the characteristics of the remaining stations in the network. The distribution of the three types of nodes suggests a hierarchical structure of the stations, where the areas with typologies of urban residential and suburban residential are located around areas with an urban mixed core typology. The LCCM allowed us to reduce the complexity inherent to each station environment, by using a means approach to analyze the clustering outputs.

To measure complementarity between the TOD nodes, the 5D concept was first considered as a framework to keep consistency with the TOD-ness measurement. However, the rules of complementarity constrain the dimension of design, distance to transit and destination accessibility. Complementarity between the nodes implies that the offer of supplies and demands of activities and places is greater between the nodes than within each node considered in isolation. Correspondence analysis was considered to be the right tool to analyze differentiation since it is based on a probabilistic method to depict the association between two variables of a contingency table. The result of the analysis of TOD typology versus Residential Housing Prices (RHP) suggested the urban mixed core nodes offer more choice in lower-price residential housing, however, since the data is based on the house unit, factors like housing condition or house size are not considered, but influence housing prices. A good replacement of this data would be the housing type linked to individual house price instead of the aggregated house price that we used. Due to data limitations RHP was adopted to reveal the differentiation in housing choices and trigger the discussion. The result of "TOD typology versus Building Use" suggests strong differentiation between the node types in terms of building uses. As the nodes are connected by the rapid transit service, the differentiation in building use between the nodes adds to the total building use diversity of the nodes, which fits well the hypothesis of complementarity between the nodes triggered by the spatial interaction promoted by the TOD network.

As a result, the node interaction based on the network synergy premise indicates that the roles of the nodes within a TOD network can be complementary as one type of node can be generally seen as providing services that other types of nodes do not supply but have a need for. For example, at the urban mixed core station, there are trains of different character and different frequency, e.g., the Intercity train travelling to destinations outside the region. The residential typology nodes are complementary to the mixed core nodes as passengers from the residential type node can transfer at the urban mixed core station to access an Intercity service.

We expect that issues of complementarity would be valid in different contexts. However, this methodology should be applied to more complex urban structures to understand whether the node typologies found for this case could also be replicated. We hypothesize that in larger urban areas and regions more variety in the typologies would be identified, which justifies applying this methodology to understand the role of each transit node within a TOD network. Factors potentially influencing the variety of typologies would include, e.g., diversity of land uses, densities of urban functions, diversity of travel behavior, population densities, land prices, and station location within the urban structure. Undeniably, 
selecting more factors to measure complementarity is necessary to fully demonstrate how the TOD nodes complement each other across different typologies. However, this paper confirms that synergy effects exist among different types of nodes within a TOD network, which is why we recommend that TOD should be assessed and planned in a network system perspective.

\section{Acknowledgements}

We thank Dr. Yamini Singh and the Province of Gelderland for providing the data for this study. 


\section{References}

Arnhem Nijmegen City Region (2018). Retrieved from https://www.denvergov.org/content/dam/denvergov/Portals/193/documents/TOD_Plan/TOD_Strategic_Plan_FINAL.pdf

Atkinson-Palombo, C., \& Kuby, M. J. (2011). The geography of advance transit-oriented development in metropolitan Phoenix, Arizona, 2000-2007. Journal of Transport Geography, 19 (2), 189-199.

Austin, M., Belzer, D., Benedict, A., Esling, P., Haas, P., Miknaitis, G., Wampler, E., Wood, J., Young, L., \& Zimbabwe, S. (2010). Performance-based transit-oriented development typology guidebook. Oakland, CA: Center for Transit-Oriented Development.

Baker, D., Washington, S., \& Turrell, G. (2014). Advance transit-oriented development typology: Case study in Brisbane, Australia. Journal of Transport Geography, 34, 54-70.

CBS. (2017). Bevolking; ontwikkeling in gemeenten met 100000 of meer inwoners, Statline online database, Netherlands Central Bureau of Statistics. Retrieved from http://statline.cbs.nl/StatWeb/?LA=nl

Calthorpe, P. (1993). The next American metropolis: Ecology, community, and the American dream. New York: Princeton Architectural Press.

Capineri, X. \& Kamann. X. (1998). Synergy in Networks: Concepts. In K. Button, P. Nijkamp, and H. Priemus (Eds.) Transport networks in Europe: Concepts, analysis, and policies (pp. 35-56). Cheltenham, UK: Edward Elgar.

Cervero, R., \& Day, J. (2008). Suburbanization and transit-oriented development in China. Transport Policy, 15 (5), 315-323.

Cervero, R., \& Kockelman, K. (1997). Travel demand and the 3Ds: Density, diversity, and design. Transportation Research Part D: Transport and Environment, 2(3), 199-219.

Cervero, R., \& Murakami, J. (2009). Rail and property development in Hong Kong: Experiences and extensions. Urban Studies, 46, 2019-2043.

Cervero, R., Murphy, S., Feerell, C., Goguts, N., \& Tsai, Y.-H. (2004). Transit-oriented development in the United States: Experiences, challenges, and prospects. Transit Cooperative Research Program (TCRP) Report 102. Washington, DC: Transportation Research Board.

Dittmar, H., \& Poticha, S. (2004). Defining transit-oriented development: The new regional building block. In H. Dittmar \& G. Ohland (Eds.), The New Transit Town: Best Practices in Transit-Oriented Development (pp. 20-55). Washington, DC: Island Press.

Ewing, R., \& Cervero, R. (2001). Travel and the built environment - a synthesis. Transportation Research Record, 1780, 87-114.

Ewing, R., \& Cervero, R. (2010). Travel and the built environment: A Meta-Analysis. Journal of the American Planning Association, 73(6), 265-294.

Ewing, R. H. (2008). Characteristics, causes, and effects of sprawl: A literature review. Urban Ecology, 21(2), 519-535.

Frank, D. L. (2000). Land use and transportation interaction: Implications on public health and quality of life. Journal of Planning Education and Research, 20(1), 6-22.

Guerra, E., Cervero, R., \& Tischler, D. (2013). Half-mile circle: Does it best represent transit station catchments? Transportation Research Record, 2276, 101-109.

Hancock, M. M. B., Shepherd, D. S., Faatz, D. J., Lopez, D. P. D., Lehmann, D. P., Burns, A., .. Duffany, B. (2014). Transit Oriented Denver, Tod Strategic Plan 2014. Denver: City of Denver. https:// www.denvergov.org/content/dam/denvergov/Portals/193/documents/TOD_Plan/TOD_Strategic_Plan_FINAL.pdf

Higgins, C. D., \& Kanaroglou, P. S. (2016). A latent class method for classifying and evaluating the performance of station area transit-oriented development in the Toronto region. Journal of Transport Geography, 52, 61-72. 
Kamruzzaman, M., Baker, D., Washington, S., \& Turrell, G. (2014). Advance transit-oriented development typology: Case study in Brisbane, Australia. Journal of Transport Geography, 34, 54-70.

Masyn, K. E. (2013). Latent class analysis and finite mixture modeling. The Oxford Handbook of Quantitative Methods, 2, 551-611.

Meijers, E. (2005). Polycentric urban regions and the quest for synergy: Is a network of cities more than the sum of the parts? Urban Studies, 42(4), 765-781.

Musterd, S., \& van Zelm, I. (2001). Polycentricity, households and the identity of places. Urban Studies, 38(4), 679-696.

Pojani, D., \& Stead, D. (2014). Dutch planning policy: The resurgence of TOD. Land Use Policy, 41, 357-367.

Ritsema van Eck, J., \& Koomen, E. (2008). Characterizing urban concentration and land-use diversity in simulations of future land use. Annals of Regional Science, 42(1), 123-140.

Singh, Y. J., Fard, P., Zuidgeest, M. H. P, Brussel M., \& van Maarseveen, M. F. A. M. (2014). Measuring transit-oriented development: a spatial multi-criteria assessment approach for the City Region Arnhem and Nijmegen. Journal of Transport Geography, 35, 130-143.

Zhang, Y., \& Guindon, B. (2006). Using satellite remote sensing to survey transport-related urban sustainability. Part 1: Methodologies for indicator quantification. International Journal of Applied Earth Observation and Geoinformation, 8(3), 149-164. 